\title{
Analysis of the Performance of Disc Brake System of Addis Ababa Light Rail Transit Using Temperature and Coefficient of Friction as a Parameter
}

\author{
Andinet Kumella Eticha \\ School of Mechanical and Industrial Engineering, Addis Ababa Institute of Technology (AAiT), Addis Ababa University (AAU), Addis \\ Ababa, Ethiopia \\ Email address: \\ andinet.kumella@aait.edu.et, andinet_kumella@yahoo.com, andinetkumella48@gmail.com

\section{To cite this article:} \\ Andinet Kumella Eticha. Analysis of the Performance of Disc Brake System of Addis Ababa Light Rail Transit Using Temperature and \\ Coefficient of Friction as a Parameter. International Journal of Mechanical Engineering and Applications. \\ Vol. 4, No. 6, 2016, pp. 205-211. doi: 10.11648/j.ijmea.20160406.11
}

Received: September 30, 2016; Accepted: October 14, 2016; Published: November 16, 2016

\begin{abstract}
Most of railroad passenger vehicles in the world equipped with disc brake system which is mounted either on the wheel for (wheel mounted) or axle on the bogie frames for (axle mounted). A disc brake is a device which is used to stop or reduce the motion of vehicles. The braking performance of the train is one of the most important factors that affect the traffic and running safety of the vehicle. Among many factors, braking performance of trains is mainly affected by temperature and $\mu$ (between brake disc and pad). The main purpose of this study is determination of nodal temperature and friction coefficient, considering different loading and operating conditions, necessary to verifying safety requirements for the movement of trains. Disc brake is modeled on Solid Works 13.0, then simulation was followed using Multi-physics ANSYS workbench 14.5 Version. The thermal transient analysis of disc braking system is performed to evaluate under service and emergency braking conditions independently for selected stations. A comparison between analytical determination of $\mu$ and Ansys analysis results shows that, the performance of the disc brake is highly affected during emergency braking conditions due to minimum stopping distance and delay time. The analysis result shows, compare to the 3 stations, the maximum nodal temperature is $413.88^{\circ} \mathrm{C}$ at station Meri/CMC 2 which is much less than from the allowable values of $800^{\circ} \mathrm{C}$. The results obtained by the simulation are satisfactory compared with those of the specialized literature Hence, a good suggestion will be given on the vehicle travelling speed based on the performance on each braking conditions where if results is obtained above the allowable value.
\end{abstract}

Keywords: ANSYS Workbench, Disc Brake, Solid Works, Thermal Transient Analysis

\section{Introduction}

Transport is one of the key sectors that play crucial roles in achieving the goals of poverty eradication and sustainable development [1]. Many of the world's large cities grew in conjunction with railways, and today, large cities cannot depend only on motor vehicles for transportation [2], but trains also have greater impact on the socio-economic development of countries in the globe. However, many of transportation problems are caused by their braking system failure. Since, Train braking is a very complex process, specific to rail vehicles and of great importance by the essential contribution on the safety of the traffic. This complexity results from the fact that during braking occur numerous phenomena of different kinds - mechanical, thermal, pneumatic, electrical, etc. The actions of these processes take place in various points of the vehicles and act on different parts of the train, with varying intensities. The major problem is that all must favorably interact for the intended scope, to provide efficient, correct and safe braking actions [3].

The braking process is in fact the matter of energy balance. The aim of braking system is to transform mechanical energy of moving vehicle into some other form, which results by decreasing of the vehicle speed. The kinetic energy is transformed into the thermal energy, by using the dry friction 
effects and, after that, dissipated into the surroundings [4].

\subsection{Braking System Requirements}

a. The brakes must be strong enough to stop the vehicle within a minimum distance in an emergency.

b. The driver must have proper control over the vehicle during braking and the vehicle must not skid.

c. The brakes must have good anti-fade characteristics i.e. their effectiveness should not decrease with constant prolonged application.

d. The brakes should have well anti wear properties.

\subsection{Types of Rail Vehicle Braking Systems}

- Air brake

- Electromagnetic Rail Brake

- Rail (eddy current) Braking systems

- Rheostatic braking (dynamic braking)

- Regenerative braking

- Based on mode of operation brakes are classified as follows:

- Hydraulic brakes.

- Electric brakes.

- Mechanical brakes.

The mechanical brakes according to the direction of acting force may be sub divided into the following two groups:

Radial brakes: - In these brakes the force acting on the brake drum is in radial direction. The radial brake may be subdivided into external brakes and internal brakes.

Axial brakes: - In these brakes the force acting on the brake drum is only in the axial direction. E.g. Disc brakes, Cone brakes.

\subsection{Disc Brake}

The disc brake is a wheel brake which slows rotation of the wheel by the friction caused by pushing brake pads against a brake disc with a set of calipers. The brake disc (or rotor in American English) is usually made of cast iron, but may in some cases be made of composites such as reinforced carbon-carbon or ceramic matrix composites. This is connected to the wheel and/or the axle. To stop the wheel, friction material in the form of brake pads, mounted on a device called a brake caliper, is forced mechanically, hydraulically, pneumatically or electromagnetically against both sides of the disc. Friction causes the disc and attached wheel to slow or stop [5], [6].

The performance of disc brake system can be defined using the coefficient of friction here the braking distance is dependent on speed, coefficient of friction and the roadway grade by applying the following formula coefficient of friction can be determined:

$$
\mu=\frac{V^{2}}{2 \times g \times l_{\text {brake }} \times 3.6^{2}}-\alpha
$$

Where:-

- $1_{\text {brake }}=$ braking distance $(\mathrm{m})$

- $\mathrm{V}=$ speed $(\mathrm{km} / \mathrm{h})$

- $\mathrm{g}=$ acceleration due to gravity $\left(9.81 \mathrm{~m} / \mathrm{s}^{2}\right)$
- $\mu=$ coefficient of friction between disc and pad

- $\alpha=$ gradient [7]

\section{Methodology}

The funnel and/or Fig. 1 shown below demonstrate the method that is used to show the detail processes in this research in a more explicit way in the following manner.

A railway disc brake is prepared in Solid Works and save as this part as Step file for Exporting into ANSYS workbench Environment.

Then the preliminary analytical analysis will be done using the different parameters that are essential in order to perform the finite element analysis.

Finally combining the 3D model of the disc brake exported in to ANSYS work bench with the preliminary analytical analysis to reach the final result using the thermal transient analysis based on finite element method.

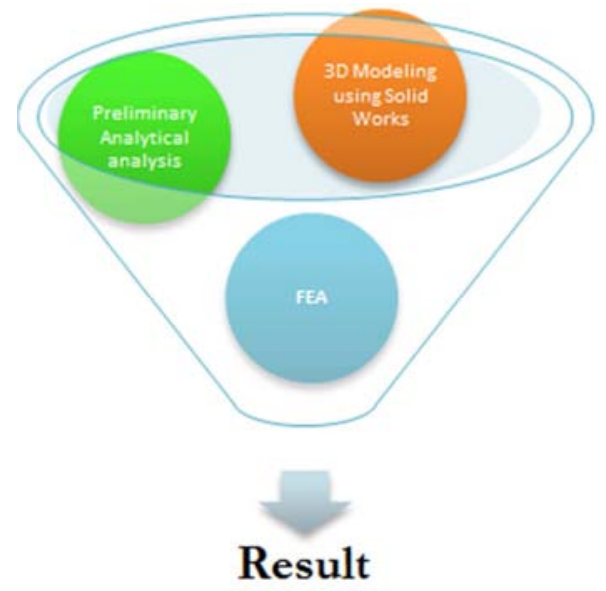

Fig. 1. Thermal transient analysis method used in the research.

\section{Solid Work Modeling of Disc Brake}

Mechanically applied disc brake system is used to bring the rail-vehicle to a final stop. Fig. 2 illustrates the assembly of disc brake system which is done on Solid works.

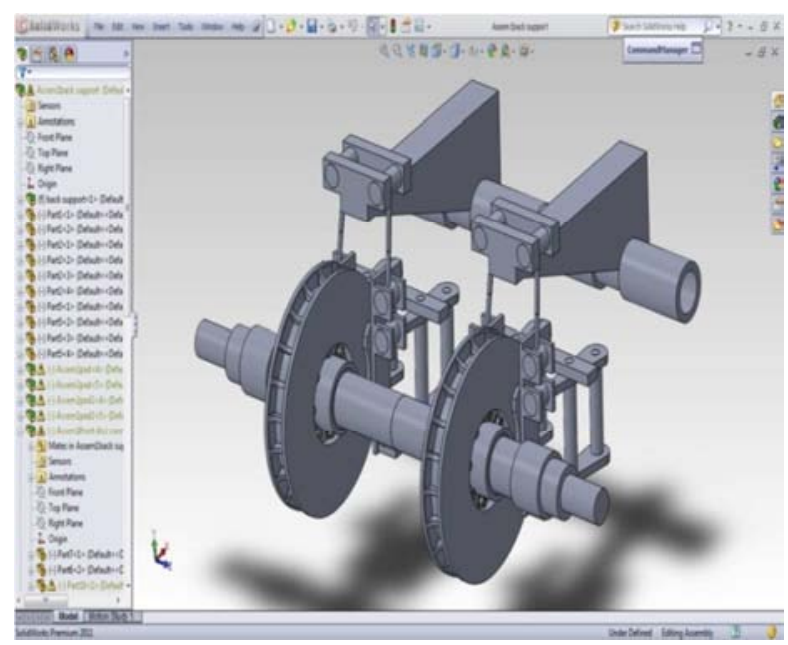

Fig. 2. Braking system assembly. 
The model of an individual component of the disc brake or (disc rotor) is shown under Fig. 3. This is done on solid works according to its specification for simulation purpose.

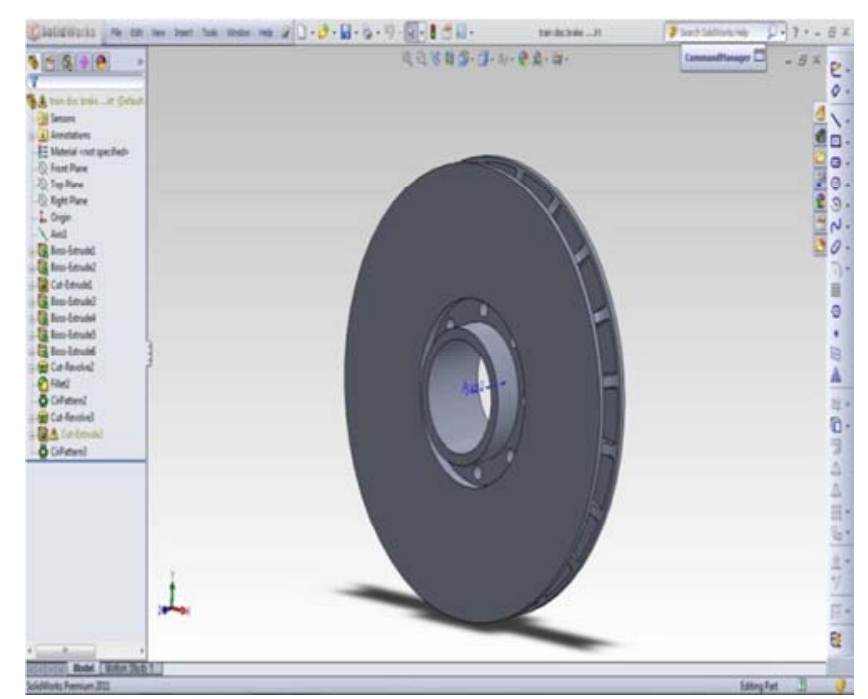

Fig. 3. Disc brake model.

\section{Preliminary Analytical Analysis}

The following table shows the material property by which the disc brake is made from.

Table 1. Material Properties of grey cast iron used for Analysis.

\begin{tabular}{ll}
\hline Density $\left[\mathrm{kg} / \mathrm{m}^{3}\right]$ & 7250 \\
Modulus of elasticity [GPa] & 138 \\
Poison's ratio & 0.28 \\
Thermal conductivity $[\mathrm{w} / \mathrm{m}-\mathrm{k}]$ & 57 \\
Specific heat capacity $[\mathrm{J} / \mathrm{kg}-\mathrm{k}]$ & 460 \\
Linear expansion coefficient $\left[\mathrm{k}^{-1}\right]$ & 0.000006 \\
Tensile strength $[\mathrm{Mpa}]$ & 430 \\
Yield stress [Mpa] & 400 \\
Thermal expansion $[\mu \mathrm{m} / \mathrm{m}-\mathrm{k}]$ & 10.85 \\
\hline
\end{tabular}

Table 2. Addis Ababa Light Rail Vehicle Properties.

\begin{tabular}{|c|c|c|}
\hline Mass of the vehicle-M [Kg] & \multicolumn{2}{|l|}{64000} \\
\hline Maximal load per axle [Kg] & \multicolumn{2}{|l|}{11000} \\
\hline Number of axles per vehicle & \multicolumn{2}{|l|}{4} \\
\hline Number of discs per axle & \multicolumn{2}{|l|}{2} \\
\hline Start speed- $\mathrm{v}_{\mathrm{o}}[\mathrm{m} / \mathrm{s}]$ & \multicolumn{2}{|l|}{22.22} \\
\hline \multirow{2}{*}{ Deceleration-a $\left[\mathrm{m} / \mathrm{s}^{2}\right]$} & \multicolumn{2}{|l|}{ Service brake $=1$} \\
\hline & \multicolumn{2}{|c|}{ Emergency brake $=1.5$} \\
\hline \multirow{5}{*}{ Braking time $-t_{s}[s]$} & station at Ayat 1 & $\begin{array}{l}\text { Service }=22.22 \\
\text { Emergency }=14.82\end{array}$ \\
\hline & \multirow{2}{*}{ station at Meri } & Service $=22.22$ \\
\hline & & Emergency $=14.82$ \\
\hline & \multirow{2}{*}{ station at $\mathrm{CMC} 1$} & Service $=22.22$ \\
\hline & & Emergency $=14.82$ \\
\hline 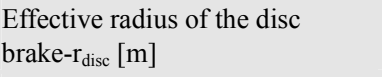 & \multicolumn{2}{|l|}{0.113} \\
\hline Radius of the wheel $-r_{\text {wheel }}[\mathrm{m}]$ & \multicolumn{2}{|l|}{0.33} \\
\hline Friction coefficient disc/pad- $\mu[/]$ & \multicolumn{2}{|l|}{0.2} \\
\hline
\end{tabular}

\subsection{Disc Brake Calculation}

Step-1:-

$$
\text { Kinetic Energy }(\text { K. ET) }=1 / 2 \times \beta \times M \times V 2
$$

$=1 / 2 \times 1.1 \times 64000 \times 22.22^{2}$ Joules

$=17.38 \times 10^{6}$ Joules

$$
\text { Potential energy }(P . E)=M \times g \times \operatorname{Sin} \alpha
$$

$=$ horizontal rail with no elevation difference at Station Ayat 1

$=64000 \times 9.81 \times 0.016$

$=10,045.44$ Joules at Station

CMC 2/Meri/

$=64000 \times 9.81 \times 0.0483$

$=30,324.672$ Joules at Station CMC 1

Total energy $=$ Kinetic Energy + Potential Energy + Rotational kinetic energy

$=17.38 \times 10^{6}-10,045.44$ Joules

$=17.37 \times 10^{6}$ Joules at CMC $2 /$ Meri

$=17.38 \times 10^{6}-30,324.672$ Joules

$=17.35 \times 10^{6}$ Joules at CMC 1

Step-2:-

Total energy $=$ Heat generated, $Q_{g}=17.38 \times 106$ Joules at Ayat $1,17.35 \times 106$ Joules at CMC 1 and $17.37 \times 106$ Joules at CMC 2/Meri

Step-3:-

Area of the rubbing faces

Step-4:-

$$
\begin{aligned}
\mathrm{A} & =2 \pi \times\left(\mathrm{r}_{\mathrm{o}}{ }^{2}-\mathrm{r}_{\mathrm{i}}^{2}\right) \\
& =0.0966 \mathrm{~m}^{2}
\end{aligned}
$$

$$
\begin{aligned}
\text { Heat Flux } & =\frac{\text { Heatgenerated }}{\text { Time } \times \text { TwicetheProjectedarea }} \\
& =\frac{17.38 \times 10^{6}}{22.22 \times 2 \times 0.0966} \frac{\mathrm{w}}{\mathrm{m}^{2}}
\end{aligned}
$$

Service brake

$$
\left.\begin{array}{rl} 
& =4.05 \times 106 \frac{w}{m^{2}} \ldots \ldots . . . . \text { station @ Ayat } 1 \\
= & 4.046 \times 106 \frac{w}{m^{2}} \ldots \ldots . . . . \text { station @ Meri/CMC } 2 \\
= & 4.04 \times 106 \frac{w}{m^{2}} \ldots . . . . . \text { station @ CMC } 1
\end{array}\right\}
$$

Emergency Brake

$$
\left.\begin{array}{c}
=6 \times 106 \frac{w}{m^{2}} \ldots \ldots \ldots . . . . . \text { station @ Ayat } 1 \\
=5.99 \times 106 \frac{w}{m^{2}} \ldots \ldots \ldots . . . .5 \text { station @ Meri/CMC } 2 \\
=5.98 \times 106 \frac{w}{m^{2}} \ldots \ldots . . . . \text { station @ CMC } 1
\end{array}\right\}
$$

Heat Flux $\left[\frac{w}{m^{2}}\right]=4.05 \times 10^{6} \times 0.75=6 \times 10^{6} \times 0.75$

$$
=3.04 \times 10^{6,} 3.03 \times 10^{6,} 3.03 \times 10^{6}
$$

Stations@ Ayat 1, CMC 2, and CMC 1

Service brake respectively. 
$=4.5 \times 10^{6}, 4.49 \times 10^{6}, 4.48 \times 10^{6}$

Stations@Ayat 1, CMC 2, and CMC 1

Emergency brake respectively.

\subsection{Initial Temperature Determination for the Next Braking Action}

The thermal capacity of disc brake is temperature dependent. The heat output of this model is composed of convection and radiation. The temperature drop of a brake rotor occurs due to the effect of station stopping time of the passengers train, accelerated and constant traveling time of the train. Therefore for the next braking action the initial temperature of the disc will rise above from its ambient temperature and will be computed according to Newton's law of cooling: -

$$
\left.\mathrm{T}=T_{\infty}+\left[\left(\mathrm{T}_{1}-\mathrm{T}_{\infty}\right) \times\left[\exp \left\{-\frac{U \times A}{M \times C}\right\} \times \mathrm{t}\right\}\right]\right]
$$

Where:

T:-cooled temperature

$\mathrm{T}_{1}$ :- maximum temperature

$\mathrm{T}_{\infty}$ :-ambient temperature

A: - disc brake contact area

$\mathrm{U}$ : - heat transfer coefficient

$\mathrm{T}$ : - delay time, station stopping, accelerated and constant travel time

M: - mass of disc

C: - specific heat capacity of grey cast iron

\section{Ansys Analysis}

ANSYS is general-purpose finite element analysis (FEA) software package. Finite Element Analysis is a numerical method of deconstructing a complex system into very small pieces (of user-designated size) called elements. The software implements equations that govern the behavior of these elements and solves them all; creating a comprehensive explanation of how the system acts as a whole. These results then can be presented in tabulated or graphical forms.

\subsection{Steps in Ansys}

To solve any problem in ANSYS it mainly follows the following steps. These are common steps to all problems except material properties and type of analysis used.

1) Preliminary decisions

a. Analysis type

b. Model

c. Element type

2) Pre processing

a. Material

b. Create or import the model geometry

c. Mesh the geometry

3) Solution

a. Apply loads

b. Solve

4) Post processing

a. Review results

b. Check the validity of the solution.

\subsection{Ansys Analysis of Disc Brake}

The disc brake which is saved as step file imported to Ansys, and then followed by mapped refined mesh which will appear as shown below.

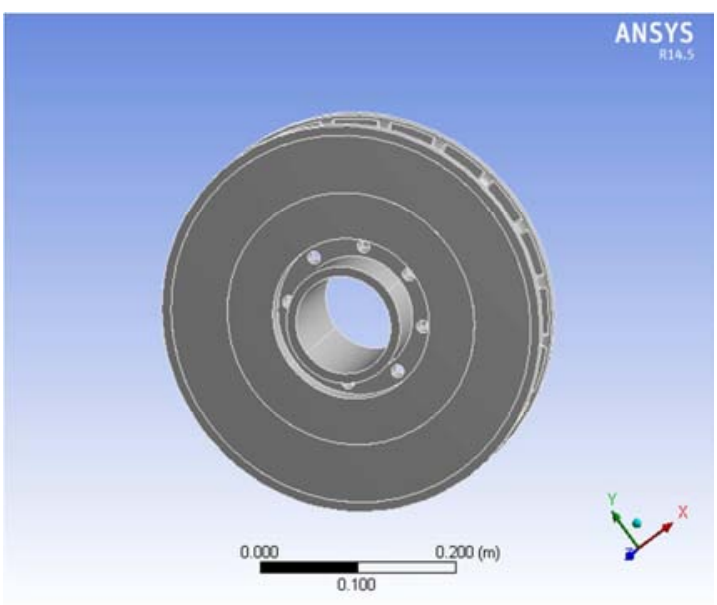

Fig. 4. Ansys Model of Disc Brake.

\subsection{Mesh Generation}

Once the disc brake model was done then it is crucial to think about to select what type of mesh will be used for the analysis purpose whether a free mesh or a mapped mesh. Compared to the free mesh, a mapped mesh is restricted in terms of the element shape it contains and pattern of the mesh. For mapped mesh, it must be build the geometry as a series of fairly regular volumes and/or areas that can accept a mapped mesh. The type of mesh generation considered here is a mapped mesh automatic generation nodes of 427,157 and 254,440 elements.

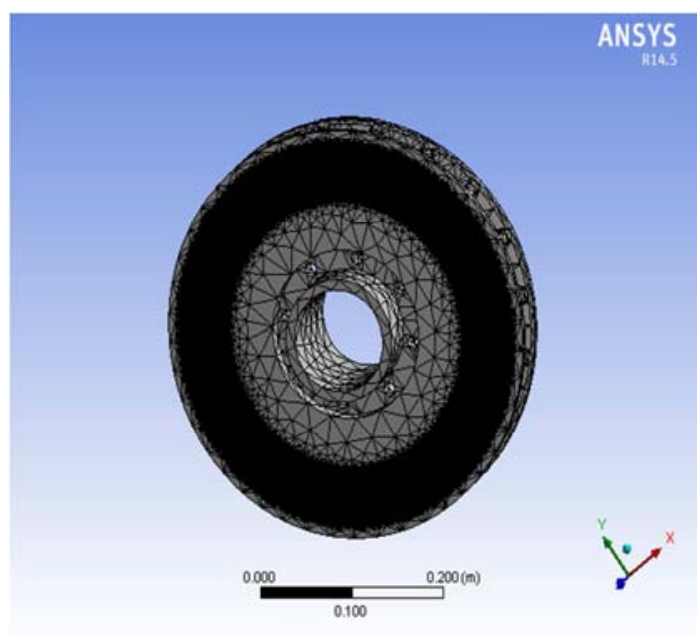

Fig. 5. Refined Mesh of the Model.

\section{Results}

For the finite element analysis 1.01 bars of pressure is used. The pressure is applied at the inner surface of the brake pad keeping bolt holes fixed in all DOF. 


\subsection{Temperature Ansys 14.5 Analysis Result}

\subsubsection{Temperature Distribution During Service Braking Condition for the 3 Stations}

The comparative result of Fig. 6, Fig. 7, and Fig. 8 shows service braking conditions for 3 stations. The nodal temperature at the 2 stations namely Meri /CMC 2 and CMC 1 are equal with $299.98^{\circ} \mathrm{C}$, however at station Ayat 1 the value is slightly less with the value of $268.96^{\circ} \mathrm{C}$. The main reason for this situation is that after the train passes station Ayat 1 relatively the value of ' $\mathrm{T}$ ' is higher than the ambient temperature, $T_{\infty}$.

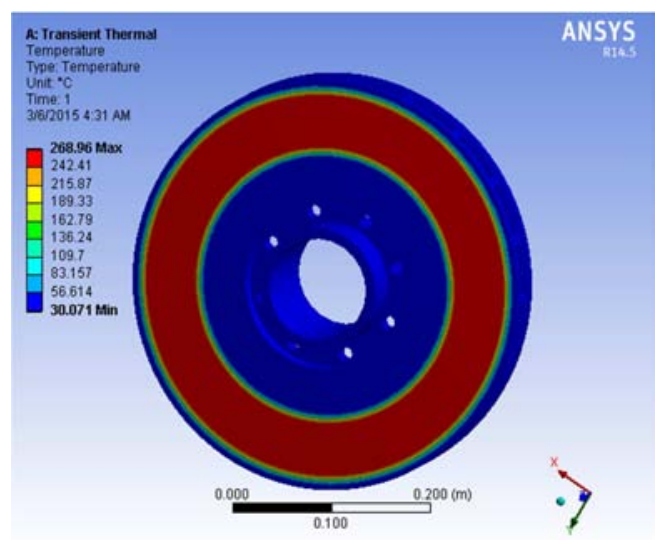

Fig. 6. Nodal Temperatures at Ayat 1.

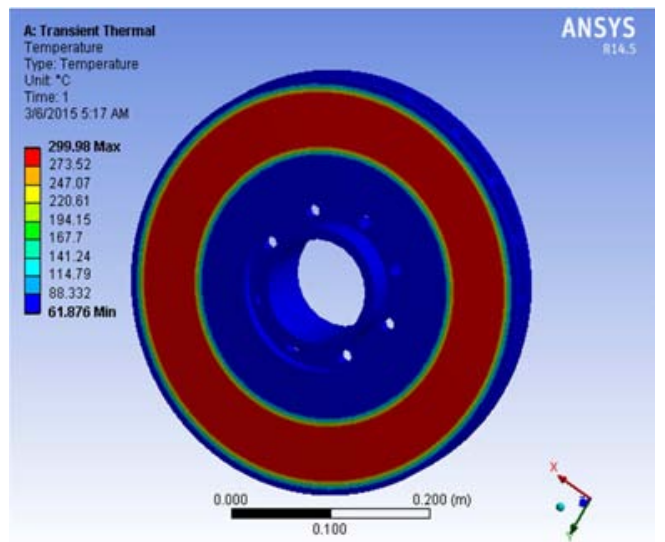

Fig. 7. Nodal Temperatures at Meri/CMC 2.

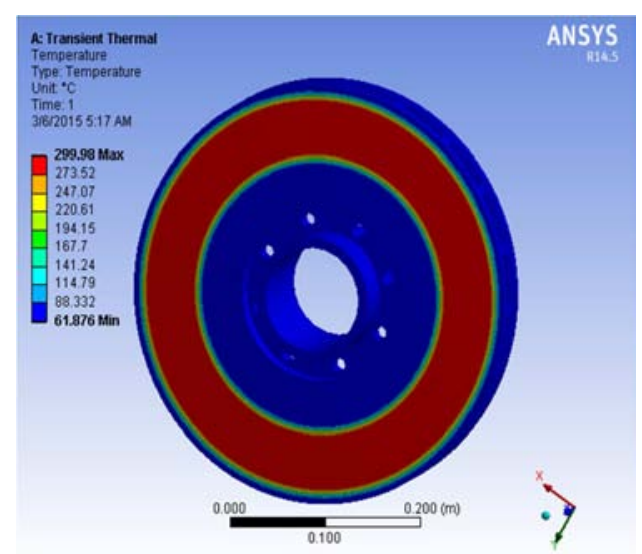

Fig. 8. Nodal Temperatures at CMC 1.

\subsubsection{Temperature Distribution During Emergency Braking Condition for 3 Stations}

During emergency braking conditions the temperature will be greater and relatively equal at stations Meri/CMC 2 and CMC 1 due to minimum stopping distance, braking time, and gradient which is illustrated under Fig. 10 and Fig. 11 respectively. However, Fig. 9 shows nodal temperature distribution at station Ayat 1 relatively with no slope condition.

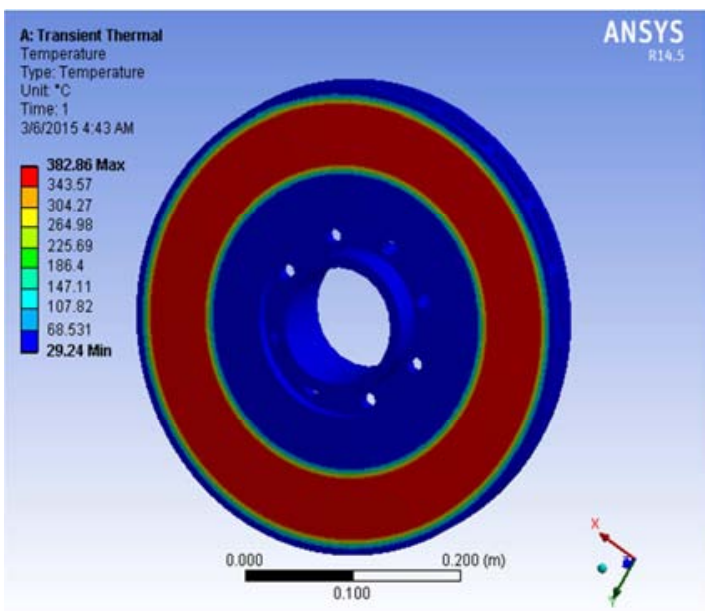

Fig. 9. Nodal Temperatures at Ayat 1.

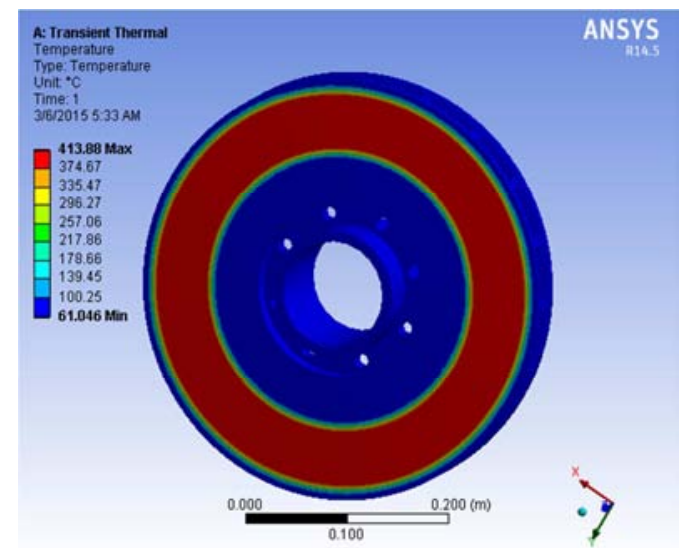

Fig. 10. Nodal Temperatures at Meri /CMC 2/.

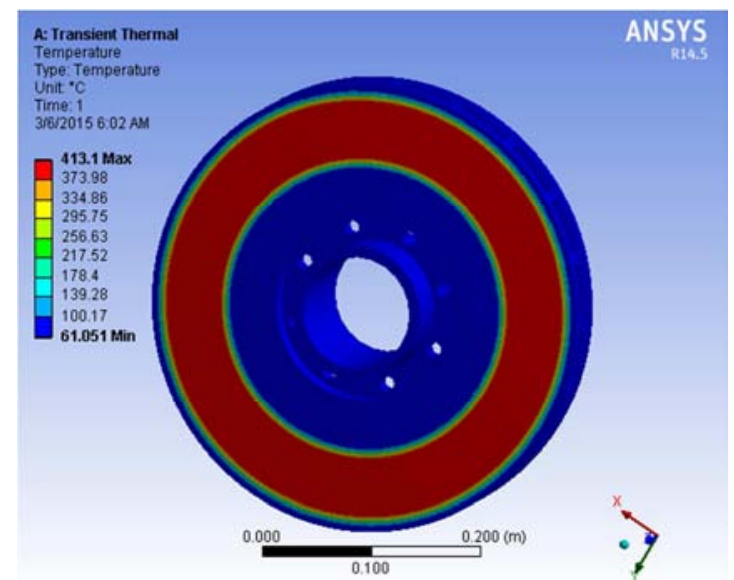

Fig. 11. Nodal Temperatures at CMC 1. 


\subsection{Coefficient of Friction Analysis Result}

Generally, the last 4 figures, [Fig. 12.-Fig. 15.] shows that during both braking conditions i.e. service and emergency braking conditions when the temperature at the contact between the brake disc and brake pad raises, the coefficient of friction will down slightly with the values as shown in their respective figures.

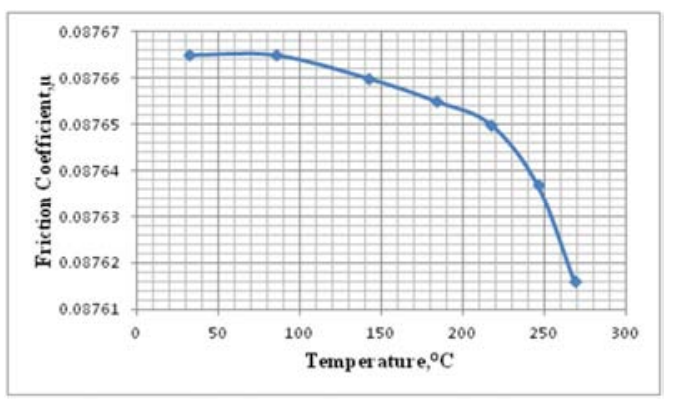

Fig. 12. Temperature vs. friction coefficient during service brake at Ayat 1.

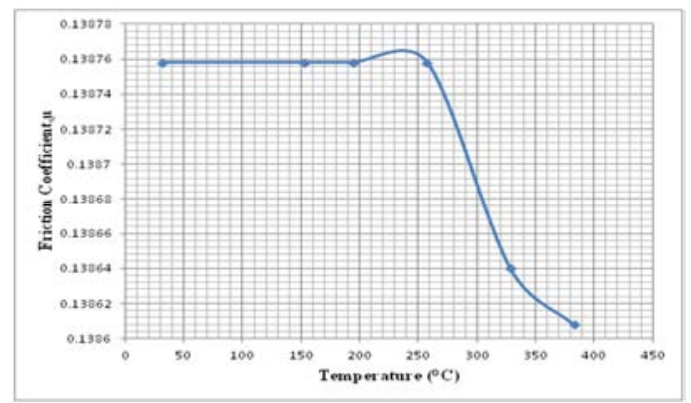

Fig. 13. Temperature vs. friction coefficient during emergency brake at Ayat 1 .

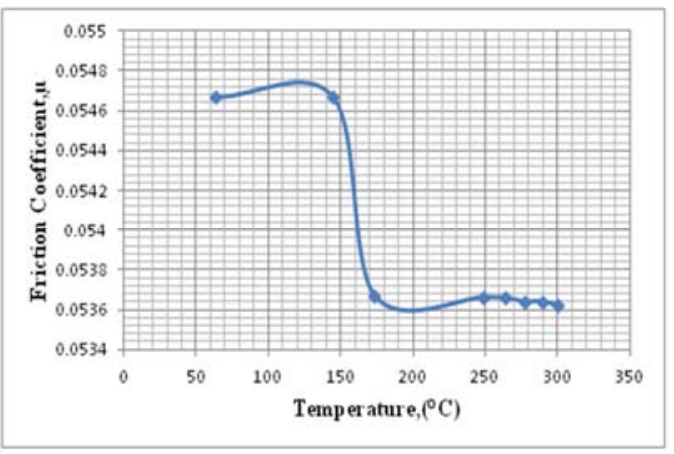

Fig. 14. Temperature vs. friction coefficientduring service brake at CMC 1.

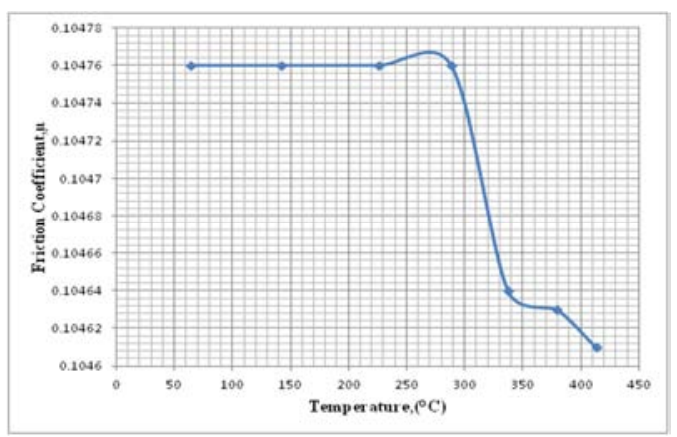

Fig. 15. Temperature vs. friction coefficient during emergency brake at CMC 1
Table 3. Results Comparison for the three stations.

\begin{tabular}{lllll}
\hline \multirow{2}{*}{ Station } & \multicolumn{2}{l}{ Temperature $\left[{ }^{\circ} \mathbf{C}\right]$} & \multicolumn{2}{l}{ Coefficient of friction, $\boldsymbol{\mu}$} \\
\cline { 2 - 5 } & $\begin{array}{l}\text { Service } \\
\text { brake }\end{array}$ & $\begin{array}{l}\text { Emergency } \\
\text { brake }\end{array}$ & $\begin{array}{l}\text { Service } \\
\text { brake }\end{array}$ & $\begin{array}{l}\text { Emergency } \\
\text { brake }\end{array}$ \\
\hline Ayat 1 & 268.96 & 382.86 & 0.088 & 0.138 \\
Meri & 299.98 & 413.88 & 0.086 & 0.136 \\
CMC 1 & 299.98 & 413.1 & 0.054 & 0.104 \\
\hline
\end{tabular}

\section{Conclusion}

I The performance of the disc brake is relatively highly affected during emergency brake due to the increment value of coefficient of friction; however for the case of service brake its efficiency is good for all 3 stations.

II At it described in the [10] when the nodal temperature between disc and pad exceeds $800^{\circ} \mathrm{C}$, severe and sudden wear of pads occurs. Practically, the thermal transient regime determines the necessity of several brake discs mounted on the wheel set, even four in the case of high speed vehicles to minimize this maximum temperature to the expected value. However the maximum temperature at station $\mathrm{CMC} 1$ which is the maximum gradient about $2.767^{\circ}$ during emergency brake of $413.1^{\circ} \mathrm{C}$ which is much less than the defined value.

III As much as possible reduce the surface temperature between disc and friction material.

- By minimizing the surface temperature there will not been occurrences of sever and sudden wear of friction materials and disc.

IV Increase the brake pad and disc contact area.

- Results improvements in heat flux generated this will produce temperature between the disc and pad to drop. Therefore this will promote the service life time of both rotor and pad materials.

\section{Acknowledgment}

I would like to thank Dr. Ing Demis Alemu and Mr. Tsegaye Feleke, Addis Ababa institute of Technology, for their support and guidance.

\section{References}

[1] UNECA. "Africa Review Report on Transport," United Nations Economic and Social Council 27-30, Addis Ababa, Ethiopia, October 2009.

[2] Norihisa Tadakoshi and Takao Okamoto, "Rail transport in the world's major Cities," Japan, October 2000.

[3] Perpinya D., Reliability and Safety in Railway, Barcelona, Spain: Intech, March 2012.

[4] Milenković, P. D. et. al, Milenković, P. D. et. al. The influence of brake pads thermal conductivity on passenger car brake system efficiency, Thermal Science: Year 2010, Vol. 14, Suppl., pp. S221-S230]. 
[5] M. R. 2. D. G. 3. V. Chengal Reddy 1,"modelingand analysis of FSAE car disc brake using fem,"vol. 3, no. 9, 2013.

[6] Daniel Das. A, C. R. R. P. B, "Structural and Thermal Analysis of Disc brake in Automobiles," vol. 2, no. 3, 2013.

[7] Poul greibet rafitec scion - DTU, July 2007, Braking distance, friction and behavior, www.trafitec.dk.

[8] Yehualaeshet Jemere, "Addis Ababa Light Rail Transit Project" July, 2012.

[9] Guru Murthy Nathi, T N Charyulu, K. Gowtham, P. Satish Reddy, "COUPLED STRUCTUAL / THERMAL ANALYSISOF DISC BRAKE."
[10] Ali Belhocine, and Mustafa Bouchetara, (August., 2012),"Investigation of temperature and thermal stress in ventilated disc brake based on $3 D$ thermo mechanical coupling model," August, 2012.

[11] Cătălin Cruceanu (2012). Train Braking, Reliability and Safety in Railway, Dr. Xavier Perpinya (Ed.), ISBN: 978- 953-510451-3, In Tech, http://www.intechopen.com/books/reliabilityand- safety-in railway/braking systems-for- railway-vehicles.

[12] Grieve D. G., Barton D. C., Crolla D. A., Buckingham J. T. (1998), Design of a lightweight automotive brake disc using finite element and Taguchi techniques, Proc. Instn. Mech. Engrs., Vol. 212, No 4, 245-254. 